\title{
Human resource management in small and medium enterprises in Portugal: rhetoric or reality?
}

\section{Pedro Ribeiro Novo Melo* and Carolina Feliciana Machado}

School of Economics and Management, University of Minho, Campus of Gualtar, 4710-057, Braga, Portugal E-mail: pmelo@eeg.uminho.pt E-mail: carolina@eeg.uminho.pt *Corresponding author

\begin{abstract}
This piece of work aims to understand the role of human resource management (HRM) at small and medium enterprises (SMEs) in Portugal, as well as to contribute to a better knowledge of this area, still briefly studied. More particularly, it aims to understand the level of implementation of human resource practices in SMEs. This research in centred on the Portuguese best 1,000 SMEs. In what concerns the method, we implemented a questionnaire addressed to the enterprises managers and utterly analysed with the statistical package for social sciences. Although we can not generalise it to the national background, this study allows us to conclude that HRM is not yet a reality in SMEs. Moreover, human resources are not seen as a strategic factor for the organisation. SMEs only apply some human resources parcelled and reactive practices, without any strategic integration. However, we can affirm, even that informally, that there exist HRM in SMEs.
\end{abstract}

Keywords: small and medium enterprises; SMEs; human resources management; HRM; small companies; recruitment; selection; training; development; performance appraisal; rewards; incentives; entrepreneurship; Portugal.

Reference to this paper should be made as follows: Melo, P.R.N. and Machado, C.F. (2013) 'Human resource management in small and medium enterprises in Portugal: rhetoric or reality?', Int. J. Entrepreneurship and Small Business, Vol. 20, No. 1, pp.117-134.

Biographical notes: Pedro Ribeiro Novo Melo is an Invited Professor at School of Economics and Management, University of Minho and School of Management at the Polytechnic Institute of Cávado and Ave, where he lectures courses of organisational behaviour and human resource management. He has a Master degree in Human Resource Management and currently is a PhD student in Business, both at University of Minho. His main areas of interest are organisational behaviour, human resource practices and its relationship with the strategy, with special emphasis on SMEs. In recent years, he focused his studies on the characterisation and development of HRM in Portugal.

Carolina Feliciana Machado received her $\mathrm{PhD}$ degree in Management Sciences (Organizational and Politics Management/Human Resources Management) from the University of Minho in 1999, and a Master degree in Management (Strategic Human Resource Management) from Technical University of Lisbon in 1994. She is teaching the human resources management subjects since 1989 
at University of Minho. Since 2004 she is an Associated Professor, with experience and research interest areas in the field of human resources management, international human resources management, training and development, management change and knowledge management. She is the Head of Management Department at the Economic and Management School at University of Minho, as well as the Head of Human Resources Management, Master and Head of Human Resources Management Work Group at the University of Minho.

\section{Introduction}

Portuguese business community is formed, mainly, by small and medium enterprises (SMEs). A study conducted by the Institute of Support for Small and Medium Enterprises and Innovation (IAPMEI) reports that approximately $97.2 \%$ of the Portuguese business and $55.4 \%$ of jobs are occupied by micro and small enterprises. The economic and social crisis that crossed the world has triggered several public debates about the importance of SMEs to the Portuguese business. For a long time, with a special emphasis during the last years, millions euros from European funds and the Portuguese Government where spent in the modernisation of SMEs. Programmes such as IQ-SME or free hands-on-training SMEs are only a few examples. For decades, SMEs were seen as companies with disqualified labour, mainly family property and using rudimentary fundamentals of management. Currently, this image tends to change, especially the various economic crises that have plagued the country and the world, which extinguishes the less prepared companies, allowing the development of technology companies and with other capacity to survive in the global market. The search for competitive factors has led business owners to invest in training for their employees, as well as in quality processes, encouraging the formalisation of all critical business processes. Areas such as marketing or human resources (HR), once neglected by employers, have gained importance in the business environment.

With the existence of a global economy, very dynamic and demanding, SMEs struggle with the need for constant change to be able to adapt and survive in the market. All the important components of a company need to find ways to increase their competitiveness and efficiency. HR may not disregard these changes. As a vital part of an organisation, HR need mechanisms, processes and practices that make them more productive, motivated and committed. Arise, then, policies and practices of human resource management (HRM) in order to convert HR in strategic resources and in line with corporate strategies. It emerges the discussion of a strategic HRM, a strategic integration with business policies (Legge, 1995).

The approach to the HRM impact on organisational performance, so far reported in the literature, has relied on research conducted in large companies. Few studies address the idiosyncrasies of small businesses. Studies of HRM in SMEs focus on HRM practices used in large enterprises, but adapted to the size, resources and culture of small businesses. Only recently, authors like Cassell et al. (2002), Kok and Uhlaner (2001) and Cardon and Stevens (2004), address the issues related to HRM in SMEs, seeking to turn them off from large companies. 
HRM has gained visibility within the SMEs. There is a change of mind-set in the business environment and the proof is in the increasing use of recruitment and selection, investment in training and development and greater relevance of the performance evaluation of employees. However, despite these changes, can we say that there are HRM in SMEs? Is it rhetoric or reality? This study seeks to focus on the idiosyncrasies of small organisations and try to understand if there are policies and practices of HRM in SMEs, allowing them to obtain a competitive advantage.

In Portugal, and according the context in which we stand, we can say that the role of HRM has gone through an evolutionary process, as it happened in other countries, which has been described and analysed by some academics. However, little is known about the HR function, as mentioned by Cabral-Cardoso (2006). Studies on HRM are scarce and those that exist are associated with large enterprises. This is the reason why the choice of this topic and its relevance are linked to some extent to the low investment in research in management of SMEs. Another interesting aspect is that, although organisations are smaller in size, HRM may appear either in an informal and unsophisticated or on a complex and highly structured form, allowing the researcher to contact with a wide variety of situations.

Portuguese business consists, mainly, of SMEs. They play an important role because they generate richness and employment (Duarte, 2002). For Cabral-Cardoso (2006) this aspect limits the development of HRM in Portugal. According to the author, structural conditions of economy, mainly composed of SMEs and family businesses, without a personnel function, does not seem to be a favourable environment for the growth of HRM in Portugal. When we try to identify whether organisations have an HR manager, size seems to be a crucial factor.

Portugal has been experiencing a transition over three decades. The country experienced a totalitarian regime during the 20th century, which had the right key 'proudly alone' (Cunha, 2005). According to Cabral-Cardoso (2006), Portugal, until 1960, can be described as a poor society, mainly land, ruled by a political elite from a small number of well-established families. After the phase of political and social turbulence experienced in the $60 \mathrm{~s}$ and $70 \mathrm{~s}$, Portugal has experienced profound changes in management and managers. During these three decades, Portugal has experienced deep changes in society and its business environment. Regarding the role and status of HR managers in recent decades there has been no major changes (CabralCardoso, 2004).

Despite significant changes, HRM role in Portugal still is essentially bureaucratic and administrative (Cabral-Cardoso, 2004). The administrative guidance to managers in Portugal is the result of a major government intervention, in a bureaucracy and a lack in customer orientation (Cunha, 2005). In Portugal, HRM is still at an early stage in its development and implementation. HR managers still seek status within the organisation that allows them to have more strategic role in management decisions (Cabral-Cardoso, 2004).

In recent years, the emergence of academic backgrounds related to HRM provided some changes in Portugal. According to Cabral-Cardoso (2006) HRM in the academic backgrounds provided an academic status to the field of HR, and better prepared managers for Portuguese organisations. The inclusion of higher-level managers in Portuguese organisations allowed a better adaptation of the American 
rhetoric to Portuguese reality (Cabral-Cardoso, 2006). As stated by Cunha (2005), some Portuguese managers are apparently trying to combine the 'best practices' in local contexts.

HRM in SMEs is, until recently, disappropriated. To this contributed little research and studies about SMEs (Reid and Adams, 2001). Recently, research on practices of HRM in SMEs increased considerably (Kok and Uhlaner, 2001), probably due to the important source of information and material of studies about SMEs that provides management researchers, the development of new theoretical approaches (Cassell et al., 2002). Several authors have suggested that HR can be a source of competitive advantage (see, for example, Barney and Wright, 1998; Cunningham and Rowley, 2007). HRM have an important role in implementing practices that benefit employees both in performance and motivation. In most cases, HRM practices benefit by the modernisation and advancement of SMEs. A study in USA proved that poor emphasis on HR in SMEs have been one of the reasons for businesses failure in the analysed companies (McEvoy, 1984).

SMEs have difficulty in implementing HRM policies and practices. A study by Heneman and Berkley (1999) confirmed that in 117 small companies, only 15 had a HR department. One reason for this is the difficulty in recruiting and retaining employees due to limited financial resources and the reluctance to lead at great cost or prohibitive practices.

Two aspects influence the definition of HRM in SMEs: informality in small companies versus formality in large companies and HRM practices of large companies adapted to small businesses.

Several studies about SMEs take them as informally organised and with informal HRM practices (Cardon and Stevens, 2004). There are contextual variables (firm size, strategy, technology and structure (Jackson et al., 1989) that predict whether there are or not HRM practices in firms and their level of formality. Until 1970, the major HRM research focused on the development of effective HRM practices in large organisations, studies that linked HRM practices and performance of HR (Kok and Uhlaner, 2001). Recently, studies examine the impact of more formal HRM practices on performance at the organisational level (see, for example, Huselid, 1995; MacDuffie, 1995). These authors researches analyse the impact of innovative HRM practices when integrated with organisational policies. They defend the model of 'best practices' (Kok and Uhlaner, 2001). Overall, firm size is related to the incidence of HRM in planning and level of formalisation of HRM (see, for example, Kok and Uhlaner, 2001; Kotey and Sheridan, 2004). Although the companies size influence HRM practices, it is not clearly, the only important factor, given the variation in formalisation of HRM practices. An empirical study conducted by Kok and Uhlaner (2001) proved the importance of company size as an indication of a formal development of HRM. Moreover, SMEs varies the types of HRM practices.

The main theoretical perspectives about 'best practices' and management systems for high performance continue to neglect small organisations (Wilkinson, 1999). However, they begin to have more empirical studies on SMEs, which, according to Baron (2003), only benefits the field of HRM. SMEs provide a context of unique business value and enhancer to test the principles and theories of HRM. To conclude, if there's a compelling financial support from local investors for private initiatives, there's clearly seamless pathway for such practices to be more attractive for SMEs (Cassell et al., 2002). 


\section{Methodology}

This research has, as its object of study, SMEs in Portugal. To analyse HRM practices present in Portuguese SMEs, we used a questionnaire, sent by mail, for a total of 512 companies.

\subsection{Goals definition}

The huge business competitiveness in the world and constant search for sources of competitive advantage has led many academic and professional studies to address it on the potential of HRM in business success. Since the vast majority of Portuguese companies are SMEs and this area standing a bit neglected by scholars and professionals, becomes relevant to analyse the management of people developed in Portuguese firms.

This study seeks to contribute to a better understanding of the real situation of HRM in Portuguese SMEs.

More specifically it seeks to:

a identify HRM policies and practices, e.g., HR planning, recruitment and selection, training and development, performance evaluation, awards and rewards

b verify the relationship between HRM and strategy

c assess the implementation level of HRM in SMEs.

\subsection{Hypothesis}

According to Gil (1995) the hypothesis has a crucial role in suggesting to the facts. These suggestions could be the solution to the problem and can be true or false.

After conducting the literature review, and based on the major empirical studies, whose results were recently presented (see, for example, Cassell et al., 2002; Cardon and Stevens, 2004; Barrett and Mayson, 2007), we propose the following hypotheses, which are to be confirmed through the analysis of data collected in questionnaire surveys.

Hypothesis 1 The larger the company, greater use of HRM practices.

According the literature, larger firms have greater organisational conditions (human, material and financial) for development of HRM. Kotey and Sheridan (2004) consider that firm size is related to the incidence in planning of HRM and its degree of formalisation. Kok and Uhlaner (2001) report that there are several variables that influence HR practices in SMEs, such as size, environment and company strategy.

Hypothesis 2 HRM practices are usually ad hoc, disintegrated from business strategy in small organisations.

The evidence shows that HRM practices tend to be regularly ad hoc in small organisations (see, for example, Wagar, 1998; Cardon and Stevens, 2004). SMEs do not incorporate a sustainable development and strategic policies, and HRM practices. Typically, HRM practices are business strategy disintegrated (Barrett and Mayson, 2007).

Hypothesis 3 All companies have some form of HRM, even if informal. 
Several studies about SMEs take them as informally organised and with informal HRM practices (Cardon and Stevens, 2004). A study by Cassell et al. (2002) suggests that there is considerable diversity in how HRM practices are implemented in SMEs and their relative success. Some HRM practices are more used than others, such as recruitment and selection, but are applied in an informal perspective, disintegrated the business strategy and with short-term results, to fill gaps in the team.

\subsection{Sample}

The sampling and, in particular, the sampling procedures, applies in various areas of knowledge and constitute, often, the only way to get information about a particular reality that know what matters. Based on the extent of study, SMEs at national level and the object of study, the sample was selected from a convenience perspective, from a database (target population) on market. The target population of the study was 'the 1,000th best SMEs' Issue 284, December 2009, from Exam magazine, which publishes, every year, a list of 1,000th's best SMEs at national level. After collecting the contact details of companies, it was found that there are a limited number of e-mails from companies, available to the general public. Further, we found that a vast number of companies does not have any website. Considering these constraints, and as we said before, there were send by e-mail questionnaires to 512 companies. From these we have received $10.1 \%$ positive questionnaires.

Sample characterisation: After collecting the surveys, it appears that companies are distributed for different sectors, with a special emphasis in manufacturing sector $(32 \%)$ and commerce $(30 \%)$.

Figure 1 Areas of activity from sample

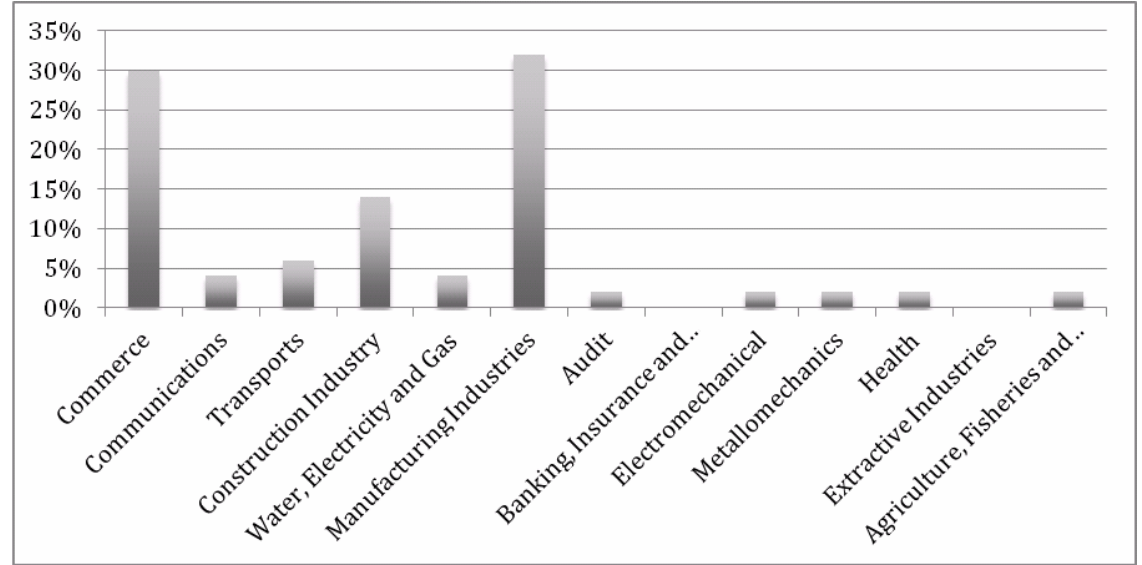

In what concerns the number of employees for each organisation, most companies surveyed have fewer than 250 employees (72\%). Organisations with more than 250 employees account for $14 \%$ of the sample, $12 \%$ with less than 50 employees, and only $2 \%$ have fewer than ten employees. Taking into account the Portuguese National Institute of Statistics, we can say that, according these numbers, $72 \%$ of the companies in study are considered medium-sized organisations. Companies with fewer than 50 employees (small organisations) represent $16 \%$ of the sample. 
Figure 2 Distribution of the number of employees

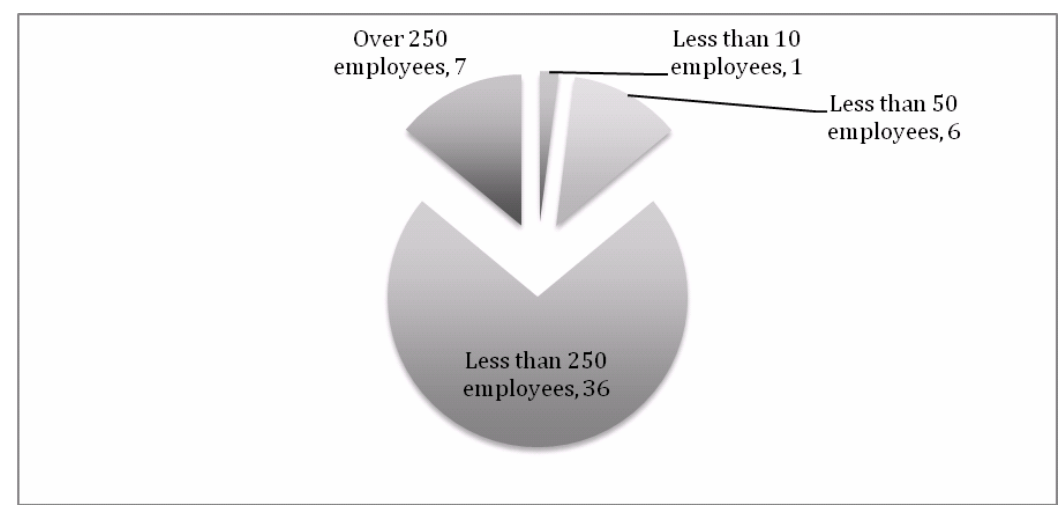

It appears, also, that most respondents are responsible for HR of companies $(74 \%)$ and $12 \%$ are general directors or managers.

Figure 3 Respondent position in company

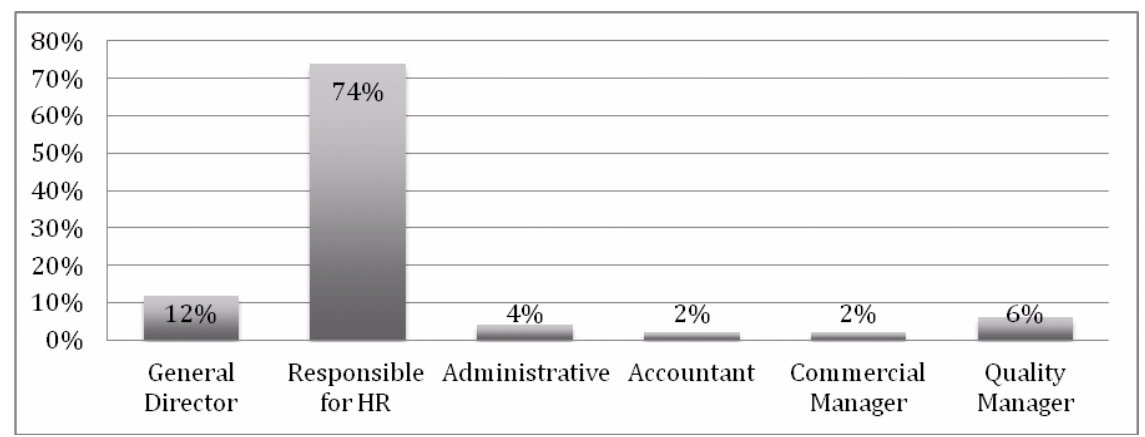

About academic qualifications, the great majority of respondents (75\%) are graduated. The lowest level of educational attainment represents $12 \%$ of the sample (secondary level). This value has great relevance for the study, as it seems to anticipate non-existence of HRM in some companies.

Figure 4 Academic qualifications

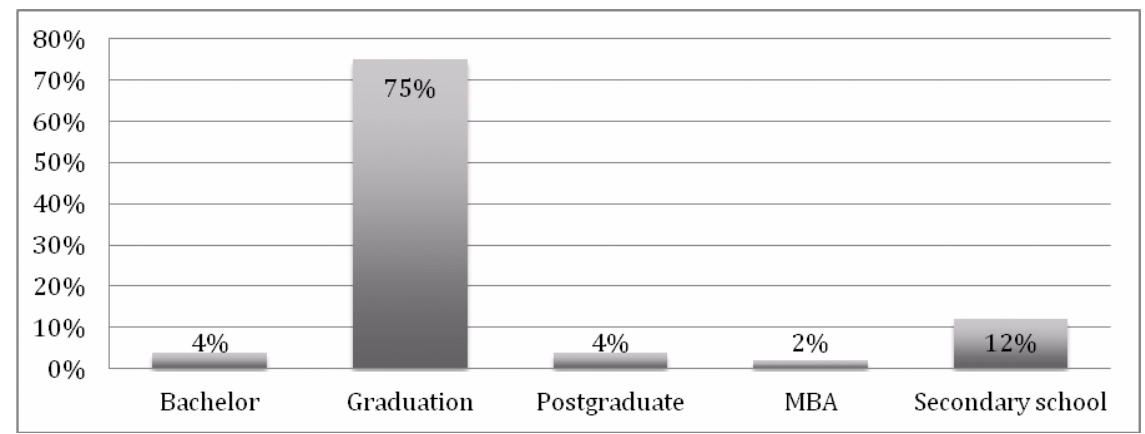


Data collection: After the initial literature review, the next step was to build an instrument to facilitate data collection for research, applied to a vast number of respondents. In this sense the instrument used to collect data was survey questionnaire. The first step was to define the variables to be analysed. The development of questionnaire survey was supported in Snell and Dean (1992), and Ramamoorthy and Carroll (1998). The number of surveys collected corresponded at $10.1 \%$ of all companies. These low values even are within acceptable limits for surveys of this type and this area. There is not a value acceptable response rate for this type of study. It is true that, the higher the better, for a systematic analysis of data (Roth and BeVier, 1998). Dennis (2003) note that one-third research of SMEs on scientific journals, between 1991 and 1995 , had a response rate below $25 \%$.

\section{Discussion}

This study aimed to understand the importance of HRM in SMEs, as well as the existing degree of formalisation, seeking the withdrawal or recall of a set of elements that allow defining SMEs reality. It also looks to understand what are the strengths and limitations of people management in small organisations.

\subsection{HRM in Portuguese SMEs: rhetoric or reality?}

The huge business competitiveness in the world and constant search for sources of competitive advantage has led many academic and professional studies to address it on potential of HRM in business success. Since the vast majority of Portuguese companies are SMEs and this area is being a bit neglected by scholars and professionals, it is important to analyse HR management and its specific features. As a point of departure for the following problem arises: Are there HRM truly strategic, structured and conceptualized or just a purely administrative management of human resource in SMEs?

There are several authors who contribute to the achievement of a possible answer to the problem. Cassell et al. (2002) report that the approach to HRM of SMEs is fragmented and more reactive than proactive, holistic or systemic. Cardon and Stevens (2004) report that responsible for companies are more concerned with their systems, telephone networks or internet platform than with culture and practices of people managers. Cabral-Cardoso (2004) states that the use of HRM name in Portuguese firms means strategic integration, e.g., greater influence at the top of hierarchy and HR practices more aligned with business. These authors present some relevant points to study, but will be able to respond to the problem at hand? Can we understand the dynamics of Portuguese companies through Anglo-Saxon conceptual frameworks? Does that reflect our business reality?

After conducting a literature review it was found that HRM in small organisations reflects a constant informality, in contrast to large organisations that have a structured management, with well defined practices and policies and evaluation mechanisms that support these practices. This relationship between small and large companies, seems to be a key aspect because HRM practices implemented in SMEs derive from practices of large 
organisations, and because it appears in literature that the larger the company (structure, resources and processes) the greater formalisation and implementation of HRM.

\subsubsection{Hypothesis 1: The larger the company, greater use of HRM practices}

In order to test the veracity of this hypothesis we have been performed several statistical tests based on Pestana and Gageiro (2008), such as Pearson correlation coefficient, Spearman correlation coefficient and measure of association symmetric ETA.

Recruitment and selection (R\&S): R\&S practices are commonly used in SMEs. Literature reports that $R \& S$ in small organisations are developed in an informal perspective, being more structured and formalised in large companies. If we relate the respondents who claim to have a recruitment plan in place, with the number of employees of companies it appears that association is not significant (Pearson's R correlation of 0.48 at a significance level of 0.742 ), e.g., there is not evidence that the higher the number of employees, the use of a higher level of recruitment. In relation to recruitment tools used by companies, they only seem to be well defined for employees at the operational level (ad placement: 68\%; personal contacts: 76\%; spontaneous contacts: $80 \%$ ), while for top managers of company that does not happen (ad placement: $22 \%$; employment agencies: $10 \%$; personal contacts: $30 \%$ ). In small and medium-sized companies, top management is very limited, mainly composed by administrator and company partners. Often, for reasons of family involvement, recruitment of top managers is perpetuated in family of administrator company. With regard to selection of employees, firms use mostly individual interviews and employee's trial period. These methods are inexpensive for companies because they need little human and financial resources. In future, the picture does not change considerably. According to the companies, individual interviews and trial period will continue to be the most commonly used selection methods. As for employee retention strategies through the correlation coefficient $R$ Pearson, a measure of association based on chi-square test for assessing the association between quantitative variables, with same negative when variance between variables go in opposite direction, and positive when they go in same direction and that takes values between -1 and 1 (Pestana and Gageiro, $2008)$, it appears that there is a moderate negative relation $(-0.4)$, statistically significant between number of employees and use of systems incentives, e.g., when one variable increases other decreased. As for more precise job description, the combination is low (0.982), with a significance level well above 0.05 . The remaining retention strategies such as, better techniques of selection, enrichment programme of tasks, improving the industry's image, the correlation coefficient is not relevant. In relation to outsourcing of HR practices stand out recruitment and training. We tried to see if the size of firms in relation to the number of employees would have some influence with regard to these practices and found, as shown in Table 1, that no practice enhances with increasing the number of employees. Thus, we conclude that firm size does not explain the use of outsourcing.

SMEs are associated with low-skilled employees. At the intersection of variables, it was found that the aspects that contribute most to low-skilled labour are inadequate training (18\%), limited progression opportunities (16\%) and competition from large companies $(12 \%)$. 
Table 1 Comparison between outsourcing practices and the number of employees

\begin{tabular}{|c|c|c|c|c|c|c|c|}
\hline & 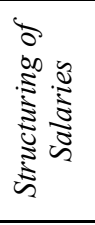 & 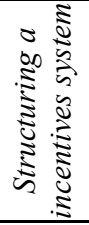 & 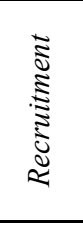 & 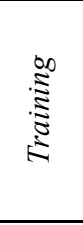 & 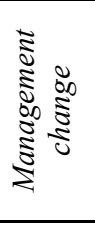 & 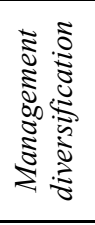 & 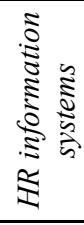 \\
\hline Less than 10 employees & 0 & 0 & 0 & 0 & 0 & 0 & 0 \\
\hline Less than 50 employees & 0 & 0 & $2 \%$ & $10 \%$ & 0 & 0 & $2 \%$ \\
\hline Less than 250 employees & $4 \%$ & $2 \%$ & $22 \%$ & $52 \%$ & $8 \%$ & $6 \%$ & $12 \%$ \\
\hline More than 250 employees & $2 \%$ & $2 \%$ & $6 \%$ & $8 \%$ & $2 \%$ & $2 \%$ & $2 \%$ \\
\hline
\end{tabular}

Training and development $(T \& D)$ : According to the literature, T\&D is the practice, in conjunction with recruitment and selection, mostly used by SMEs. The empirical study has proven this perspective therefore, $82 \%$ of companies have an effective training plan. Crossing the variables 'The organisation has an effective training plan' and 'Methodology training' it appears that those who stated they had an ongoing training plan also stated they had a defined methodology. By crossing the variables 'the organisation has an effective training plan' and 'it uses external professionals' denotes that most companies resort to external training companies. Training in SMEs is described as informal and developed in the workplace, with little or no management involvement (Kotey and Sheridan, 2004). Through the frequency analysis it appears that $54 \%$ of companies use currently training in the workplace and 38\% currently use and will use in the future. In respect of training provided, data shows that training methods are diversified and structured as training in classroom (54\% currently use), computer-aided training $(30 \%)$, video training $(24 \%)$, auto-didactic training (12\%), personal training $(40 \%)$ and training abroad $(40 \%)$. Literature about SMEs suggests that managers of small companies assess the value of training in their company in an informal way and tend to use various types of subjective assessments (Jameson, 2000). Relating this view with data from questionnaires, this idea is not so clear, because $64 \%$ of companies assess trainees at the end of training course, $68 \%$ rate the job performance and $54 \%$ of companies evaluate training results. However, such evaluations are mostly used by medium-sized companies (250 employees). By crossing the variables 'training evaluation' and 'number of employees' it denotes a greater incidence of assessment of training in enterprises with 250 or more employees. It is important to enhance the very small number $(2 \%)$ of companies that does not use an assessment methodology. The decision of not develops training programmes in company, can be, not infrequently, originated by the idea that it does not bring short-term outcomes. Company management tends to consider training as expensive and ineffective, remaining very septic's about the benefits of training (Wong et al., 1997). When asked about the future of training budget, it appears that $53 \%$ of companies that have effective training plan will moderately increase the training budget, while $33 \%$ of companies will not increase it. The correlation between 'training plan effective' and 'training budget' shows a moderate positive association with the correlation coefficient of Pearson's R of 0.473 , statistically significant at a significance level of 0.05 .

Performance appraisal: Employee's performance appraisal is, increasingly, a crucial factor for companies. In this sense, we intended to meet the critical factors to implementation process in companies, such as: if the variable 'performance evaluation' 
and 'number of employees' are associated; which factors have the greatest impact on improving productivity; and what degree of practices formalisation in companies. First, we tried to analyse the degree of formalisation of this practice in SMEs. Literature states that the application of the process of performance appraisal in SMEs is not peaceful and there are several barriers to its development. According to Hudson et al. (2001) the main barriers for non-implementation of the process of performance appraisal in SMEs are limited resources and the most dynamic and emerging style that characterises these companies. These aspects are problematic because the development of performance evaluation process is necessarily long term and requires results to be strategic. Through data analysis it appears that there is not association between the variable 'performance appraisal' and 'number of employees' (R Pearson of -0.067 , with a significance level of 0.64). For the methods used by companies to assess its employee's performance, there is a greater focus on use of self-evaluation in top management, and this group has the highest percentage in non-use of an assessment. There is a higher incidence of assessment by the superior, especially for operational staff $(82 \%)$. The methods that are more structured and require more financial and material resources, such as 360-degree assessment and evaluation by customers have a low utilisation rate in all groups of employees, as shown in Table 2. These results seem to indicate a low formalisation of performance appraisal in organisations.

Table 2 Methods/techniques of performance appraisal

\begin{tabular}{|c|c|c|c|c|}
\hline & 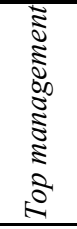 & 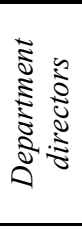 & $\begin{array}{l}5 \\
.5 \\
\vdots \\
\vdots \\
5 \\
5 \\
5\end{array}$ & 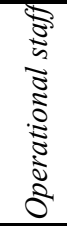 \\
\hline Self-assessment & $34 \%$ & $30 \%$ & $24 \%$ & $28 \%$ \\
\hline Assessment by the superior & $16 \%$ & $54 \%$ & $66 \%$ & $82 \%$ \\
\hline Peer assessment & $10 \%$ & $10 \%$ & $8 \%$ & $12 \%$ \\
\hline Assessment made by subordinates & $10 \%$ & $20 \%$ & $12 \%$ & $4 \%$ \\
\hline Assessment made by customers & $16 \%$ & $28 \%$ & $14 \%$ & $20 \%$ \\
\hline 360-degree assessment & $6 \%$ & $14 \%$ & $6 \%$ & $4 \%$ \\
\hline Evaluation is not performed & $26 \%$ & $10 \%$ & $10 \%$ & $12 \%$ \\
\hline
\end{tabular}

At last we tried to find out which factors have the greatest impact on improving productivity. Increasingly, companies associated performance with pay, or compensation based on performance, in order to improve productivity and make their employees more efficient. $68 \%$ of companies said they would increase the rate of pay. But, taking into account the number of companies that do not perform evaluation and the assessment method they use, it will be a little difficult to implement performance-based compensation.

Rewards/incentives: The systems of rewards/incentives have an important role in enterprises. For small businesses its incentives are an important practice (Cassell et al., 2002) because it often has an influence on SMEs efforts in what concerns recruitment and retention of HR (Cardon and Stevens, 2004). The use of incentive programmes as a retention strategy is seen by $70 \%$ of respondents as having a high or very high efficacy, from whose $32 \%$ sees monetary strategies. Companies who claim to have no incentive 
system $(10 \%)$ describe the retention strategies, namely, greater benefits, increased pay, increased number of very effective non-monetary rewards. Wagar and Langrock (2004) suggest that the best way to predict the presence of specific programmes of compensation is the size of business, having the largest companies the resources to invest in these programmes. To test this assertion, we used the statistic test, $R$ Pearson. The correlation shows a low negative correlation $(R=-0.318)$ and was statistically significant $(0.02)$ between 'productivity bonuses and incentives' and 'number of employees'. Regarding the variables 'performance bonuses' and 'number of employees', the correlation coefficient $R$ Pearson reveals a very low negative correlation $(R=-0.077)$, not statistically significant $(0.59)$. The results did not reveal any relationship between increase in number of employees and increase use of bonuses and incentives. Incentives can be monetary and non-monetary. Most companies bet more on monetary rewards, however, it has acquired non-monetary relevance. Companies are betting more on cash bonuses in detriment of non-monetary rewards. When asked about the future, reality is reversed, with greater reliance on non-monetary rewards. Currently, small firms are betting bonuses in cash because they allow simplifying the system of incentives and also reducing HR, under the administrator or manager of the company monitorisation. These data allow concluding that awards and rewards are simple (Ghobadian and Gallear, 1996) and informal (Wagar and Langrock, 2004).

In order to test the hypothesis 'The bigger the company greater use of HRM practices', allowing also give credibility to data analysed above, we used the statistical test ETA. The statistical test ETA is a measure that allows us to observe the association between variables. The ETA2 represents the proportion of variation in the dependent variable that is explained by the independent variable (Pestana and Gageiro, 2008). Calculating the measure of association ETA for all points above it appears that:

- there is an association relation between the variable 'recruitment and selection plan for the company' and the variable 'number of employees of the company' - ETA equal to 0.241 ; ETA2 equal to $6 \%$

- there is an association relation between 'budget evolution for training in the medium and long term' and the variable 'number of employees of the company' - ETA equal to 0.256 ; ETA2 equal to $7 \%$

- there is an association relation between the variable 'evolution of the reward based on performance' and the variable 'number of employees of the company' - ETA equal to 0.141 ; ETA2 equal to $2 \%$

- there is an association relation between the variable 'performance appraisal' and the variable 'number of employees of the company' - ETA equal to 0.150; ETA2 equal to $2 \%$

- there is an association relation between the variable 'productivity bonuses and incentives' and the variable 'number of employees of the company' - ETA equal to 0.382 ; ETA2 equal to $15 \%$.

It appears that in all variables the association is weak (Pestana and Gageiro, 2008), considering that only between $0.6 \%$ and $15 \%$ of variation in the defined variables is due to firm size. The evidence on size of business and HRM practices does not allow accepting the hypothesis 'The bigger the company, greater use of HRM practices'. 


\subsubsection{Hypothesis 2: HRM practices are usually ad hoc, disintegrated from business strategy in small organisations}

The debate of HRM in SMEs arises inevitably associated with the degree of formalisation of practices. The new interest in HR as strategic to organisation seeks to establish a framework for HR with an important role in wealth creation, directly contributing to the implementation of strategic and operational objectives for organisation (Becker and Gerhart, 1996).

In realm of 'business strategy' and 'HRM practices', the results indicate that there is some conformity between variables. However, in long-term planning, HR is the fourth priority, which reveals inconsistency. Business strategy, capital and technology emerge as top priorities for companies. Statistically significant at a significance level of 0.01 , Friedman test applied to different variables of the process of long-term planning confirm that in terms of averages, there is a clear preference among the variables, and that people have an average value of 5.04, technology 3.96 and capital, 4.96.

There are several variables that influence HR practices in SMEs, such as size, environment and strategy (Kok and Uhlaner, 2001). Since the relationship, company size and HRM practices were studied before, this analysis, now, will focuses the environment and company strategy. By crossing the variables 'overall business strategy' and 'role of HR manager' is possible to observe that respondents who define HRM totally related to the overall business strategy identifies HR manager as a business partner. But, more than $50 \%$ of respondents have this scenario as the future in company.

Those consulted that describe the association HRM and overall business strategy as being more or less related, identifies HR manager as an administrative specialist and a change agent, which latter is presented as a future aspiration. In order to test the correlation between companies that define HR manager as a strategic partner and the degree of implementation of the main HRM practices was used Spearman correlation coefficient that had as result a negative association in all HR practices. That is:

- there is an association relation between the variable 'strategic partner' and the variable 'recruitment and selection' $-\mathrm{S}=-0.271$, with a significance level of 0.18

- there is an association relation between the variable 'strategic partner' and the variable 'performance evaluation' $-\mathrm{S}=-0.247$, with a significance level of 0.22

- there is an association relation between the variable 'strategic partner' and the variable 'conception and design of training programmes and content' $-\mathrm{S}=-0.10$, with a significance level of 0.63

- there is an association relation between the variable 'strategic partner' and the variable 'management skills' $-\mathrm{S}=-0.205$, with a significance level of 0.32

- there is an association relation between the variable 'strategic partner' and the variable 'productivity bonuses and incentives' $-\mathrm{S}=-0.239$, with a significance level of 0.23 .

The results are not conclusive because correlations are very weak and significance level is much higher than 0.05 (Pestana and Gageiro, 2008). 
Asked what are the most critical aspects of HRM in near future, respondents reported focus on customer satisfaction and improved employee productivity. In order to further examine this issue we crossed the variable 'performance evaluation' and 'improving productivity'. $65 \%$ of companies, which have the most critical aspect of improving productivity, develop performance assessment with the involvement of HR department. The same happens at the intersection of variables 'productivity bonuses' and 'performance bonuses' to 'improving productivity'. 59\% of companies implement the productivity bonuses with the involvement of HR department and $58 \%$ in relation to performance bonuses. The results are similar when using the variables 'employee satisfaction' and 'importance in people'. 44\% of companies that define the satisfaction of employees as critical to company claim to have employees as very important for the longterm planning.

For the analysis conducted it seems to exist in SMEs, informal practices that support the management of company but disintegrated from business strategy, which led us to accept the second hypothesis.

\subsubsection{Hypothesis 3: All companies have some form of HRM, even if informal}

A study conducted by Cassell et al. (2002) suggests that there is considerable diversity in how HRM practices are implemented in SMEs, and their relative success. SMEs have low material, financial and HR, which limits the implementation of HR practices. Despite the diversity of SMEs and their limitations, several authors argue that there are conditions for implementation of HR practices. Some HRM practices are used more than others, such as recruitment and selection. Clearly, these practices have few implications in terms of resources, which facilitates its implementation. Data collected show that, despite known limitations, $90 \%$ of companies have an HR department. In respect of practices, as can be seen in Table 3, they are implemented in companies with the involvement of HR department.

Table 3 HRM practices

\begin{tabular}{|c|c|c|c|}
\hline & $\begin{array}{l}\frac{0}{0} \\
0 \\
: 0 \\
\vdots \\
0 \\
0 \\
0 \\
z\end{array}$ & 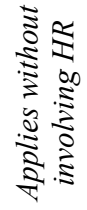 & 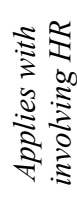 \\
\hline Recruitment and selection & $6 \%$ & $10 \%$ & $84 \%$ \\
\hline Performance appraisal & $18 \%$ & $16 \%$ & $66 \%$ \\
\hline Job design & $26 \%$ & $34 \%$ & $40 \%$ \\
\hline Qualifications of functions & $18 \%$ & $22 \%$ & $58 \%$ \\
\hline Diagnosis of training needs & $2 \%$ & $22 \%$ & $72 \%$ \\
\hline Planning of training activities & $4 \%$ & $24 \%$ & $68 \%$ \\
\hline Design and program design and content of training & $14 \%$ & $16 \%$ & $64 \%$ \\
\hline Training process assessment & $8 \%$ & $12 \%$ & $80 \%$ \\
\hline Team-work & $18 \%$ & $36 \%$ & $28 \%$ \\
\hline Orientation and training of recently admitted & $10 \%$ & $24 \%$ & $62 \%$ \\
\hline
\end{tabular}


HRM practices (continued)

\begin{tabular}{lccc}
\hline & & & \\
& & & \\
& & & \\
Management fees & $46 \%$ & $22 \%$ & $32 \%$ \\
Career plans & $6 \%$ & $46 \%$ & $48 \%$ \\
Rewards and incentives for productivity & $24 \%$ & $32 \%$ & $44 \%$ \\
Performance bonuses & $36 \%$ & $22 \%$ & $42 \%$ \\
Downsizing plans & $2 \%$ & $42 \%$ & $50 \%$ \\
Management employee costs & $36 \%$ & $38 \%$ & $22 \%$ \\
TQM & $32 \%$ & $24 \%$ & $40 \%$ \\
Management by objectives & $24 \%$ & $32 \%$ & $44 \%$ \\
Workforce planning & $4 \%$ & $12 \%$ & $84 \%$ \\
Safety and hygiene at work & $14 \%$ & $40 \%$ & $46 \%$ \\
Functional flexibility and versatility & $26 \%$ & $18 \%$ & $54 \%$ \\
Flexible schedules practices & $10 \%$ & $34 \%$ & $56 \%$ \\
Search for effective descending and ascending communication & $34 \%$ & $30 \%$ & $32 \%$ \\
Empowerment & $28 \%$ & $32 \%$ & $34 \%$ \\
Participative management & $20 \%$ & $22 \%$ & $52 \%$ \\
Skills management & & & $56 \%$ \\
\hline
\end{tabular}

Although only $33 \%$ of the companies consider employees as very important for long-term planning, $66 \%$ did not have a recruitment plan, 16\% consider HR manager as expert administration, $76 \%$ use personal contacts to hiring of employees, operational, $18 \%$ consider inadequate training, and $82 \%$ use performance appraisal by the superior, the truth is that there is some form of HR management, even more informal and with greater impact than other SMEs analysed. Thus, based on data presented is accepted Hypothesis 3.

\section{Conclusions}

This research falls within the scope of the study on HRM in Portugal and aims to evaluate the reality of HRM in SMEs, including the identification and analysis of existence of HRM practices and respective degree of implementation.

The contribution of different authors on study of reality in question is mainly done to international level because there are not studies at national reality, which does not allow drawing conclusions and establish important hypothesis. Even at international level, research is meagre when directed to HRM in SMEs. There is a set of fragmented studies that do not allow removing accurate information about the reality of SMEs. The studies of authors (Cardon and Stevens, 2004; Cassell et al., 2002) have provided another perspective on impact of HRM practices to reality of SMEs. Cardon and Stevens (2004) 
report that all SMEs have some form of HRM, even if informal. More, according to Cassell et al. (2002) there is a great diversity in the implementation of HRM practices in SMEs, and their relative success. SMEs approach to HRM is made case by case and in a reactive way, as opposed to a holistic, proactive or systemic basis.

Based on the existing literature, a survey by questionnaire was conducted to Portuguese SMEs in order to understand the organisation and business strategy of SMEs, HRM practices used and their specificities as well as the relationship between them.

Concerning the organisation and business strategy of SMEs we found that people take little importance in long-term planning at least compared with capital and technology. However, most respondents stated that the overall business strategy is completely interrelated with HRM.

The recruitment and selection practices are commonly used in SMEs. Data confirm that, $84 \%$ of firms surveyed make use of recruitment and selection. Planning recruitment is a critical step in the strategy of companies. In this research only $34 \%$ of respondents reported having a recruitment plan and $66 \%$ of them stated that there is no HR planning. In relation to recruitment tools used by companies, they only seem to be well defined for the operational-level employees. In what concerns the selection of employees, firms use mostly individual interviews and trial period. Selection methods less used in SMEs are handwriting analysis, tests of integrity/honesty, and tests for drug use. A key problem of SMEs is to compete with large companies in the attractiveness and working conditions. Thus, employee retention becomes a challenge and a gamble the businessmen, who need to use incentives and improve working conditions. Outsourcing is a practice uncommon in SMEs, only used for training and development.

In regard to training and development, this is mainly given in workplace or in a classroom. Training is a practice widely used in SMEs. Around 82\% of companies have an effective training plan. The training stages (for example, needs analysis, training assessment) are used in implementation of training, and programme evaluation is most often used in companies with 250 or more employees. Despite the importance of training budget will not increase in most SMEs.

With respect to performance assessment, we can conclude that this practice is implemented on an informal way. About the methods used by companies to evaluate the performance of its employees, there is a greater focus on use of self-assessment, on top management. There is a higher incidence of assessment by superior, especially for operational staff. Methods that are more structured and require more financial and material resources, such as 360-degree assessment have a low utilisation rate. With regard to compensation based on performance, more than half of the companies responded that this would increase.

As part of incentive, firms use more monetary rewards than non-monetary. Small companies are betting bonuses in cash because it allows simplifying the system of incentives. The use of incentive programmes, such as retention strategy, is seen by most respondents as having a high or very high efficiency. Incentive systems allow companies a solution to retain vital HR. Most SMEs have simple systems and informal rewards.

Respondents seem to have notion of the importance of HRM for their companies, but its implementation on the ground is not very evident. There are HR practices, but in a piecemeal and little strategic. Recruitment and selection, as well as training and development practices seem to be more developed. Nevertheless, there seems to be a constant informality in all-critical processes in the development of HRM. 
As regards the hypothesis testing, they have not been fully confirmed by empirical study. The first hypothesis 'The bigger the company, greater use of HRM practices' was not positive. Data allow us to confirm that there is not firm size (number of employees) that explains the existence of HR practices. The second hypothesis, 'HRM practices in SMEs are often 'ad hoc' disintegrated from business strategy in small organisations' was confirmed. Although most companies mention that overall business strategy is completely interrelated with HRM, the fact is that intersection of key variables shows otherwise. The last hypothesis, 'All SMEs have some form of HRM, even if it is informal', was also confirmed. Most companies have some form of HRM, even unstructured and piecemeal. There are companies that invest more in recruitment and selection, while others invest in training and development, performance evaluation and incentives.

The results of empirical analysis do not allow us to reaffirm, categorically, about the existence of rhetoric or reality of HRM in SMEs. The truth is that, to define HRM in SMEs is necessary to mention that this is developed informally and has no strategic integration with business.

\section{References}

Barney, J.B. and Wright, P.M. (1998) 'On becoming a strategic partner: the role of human resources in gaining competitive advantage', Human Resource Management Journal, Vol. 37, No. 1, pp.31-46.

Baron, R.A. (2003) 'Human resource management and entrepreneurship: some reciprocal benefits of closer links', Human Resource Management Review, Vol. 13, pp.253-256.

Barrett, R. and Mayson, S. (2007) 'Human resource management in growing small firms', Journal of Business and Enterprise Development, Vol. 14, No. 2, pp.307-320.

Becker, B. and Gerhart, B. (1996) 'The impact of human resource management on organizational performance: progress and prospects', Academy of Management Journal, Vol. 39, No. 4, pp.779-801.

Cabral-Cardoso, C. (2004) 'The envolving Portuguese model of HRM', International Journal of Human Resource Management, Vol. 15, No. 6, pp.959-977.

Cabral-Cardoso, C. (2006) 'Portuguese management between global rhetoric and local reality', Management Research, Vol. 4, No. 3, pp.193-204.

Cardon, S.M. and Stevens, C.E. (2004) 'Managing human resources in small organizations: what do we know?', Human Resource Management Review, Vol. 14, pp.295-323.

Cassell, C., Nadin, S., Gray, M. and Clegg, C. (2002) 'Exploring human resource management practices in small and medium sized enterprises', Personnel Review, Vol. 31, No. 6, pp.671-692.

Cunha, M.P. (2005) 'Adopting or adapting? The tension between local and international mindsets in Portuguese management', Journal of World Business, Vol. 40, No. 2, pp.188-202.

Cunningham, L.X. and Rowley, C. (2007) 'Human resource management in Chinese small and medium enterprises: a review and research agenda', Personnel Review, Vol. 36, No. 3, pp.415-439.

Dennis, W.J. (2003) 'Raising response rates in mail surveys of small business owners: results of an experiment', Journal of Small Business Management, Vol. 41, No. 3, pp.278-295.

Duarte, N. (2002) 'Creation of SMEs in northern region from program RIME during QCA II', Management and Development, Vol. 11, pp.57-80.

Ghobadian, A. and Gallear, D.N. (1996) 'Total quality management in SMEs', International Journal of Management Science, Vol. 24, No. 1, pp.83-106. 
Gil, A.C. (1995) Methods and Techniques in Social search, Atlas Publishers, São Paulo.

Heneman, H.G. and Berkley, R.A. (1999) 'Applicant attraction practices and outcomes among small businesses', Journal of Small Business Management, Vol. 37, No. 1, pp.53-74.

Hudson, M., Smart, A. and Bourne, M. (2001) 'Theory and practice in SME performance measurement systems', International Journal of Operations \& Production Management, Vol. 21, No. 8, pp.1096-1115.

Huselid, M. (1995) 'The impact of human resource management practices on turnover, productivity, and corporate financial performance', Academy of Management Journal, Vol. 38, No. 3, pp.635-672.

Jackson, S.E., Schuler, R.S. and Rivero, J.C. (1989) 'Organizational characteristics as predictors of personnel practices', Personnel Psychology, Vol. 42, pp.727-786.

Jameson, S.M. (2000) 'Recruitment and training in small firms', Journal of European Industrial Training, Vol. 24, No. 1, pp.43-49.

Kok, J. and Uhlaner, L.M. (2001) 'Organization context and human resource management in the small firm', Small Business Economics, Vol. 17, pp.273-291.

Kotey, B. and Sheridan, A. (2004) 'Changing HRM practices with firm growth', Journal of Business and Enterprise Development, Vol. 11, No. 4, pp.474-485.

Legge, K. (1995) Human Resource Management, Rhetorics and Realities, MacMillan Business, London.

MacDuffie, J.P. (1995) 'Human resources bundles and manufacturing performance: organizational logic and flexible production systems in the world auto industry', Industrial and Labor Relations Review, Vol. 48, No. 2, pp.197-221.

McEvoy, G.M. (1984) 'Small business personnel practices', Journal of Small Business Management, Vol. 22, No. 4, pp.1-8.

Pestana, M.H. and Gageiro, J.N. (2008) Data Analysis For Social Sciences: The Complementarity of SPSS, Sílabo Publishers, Lisbon.

Ramamoorthy, N. and Carroll, S.J. (1998) 'Individualism/collectivism orientations and reactions toward alternative human resource management practices', Human Relations, Vol. 51, No. 5, pp.571-588.

Reid, R.S. and Adams, J.S. (2001) 'Human resource management: a survey of practices within family and non-family firms', Journal of European Industrial Training, Vol. 25, No. 6, pp.310-320.

Roth, P.L. and BeVier, C.A. (1998) 'Response rates in HRM/OB survey research: norms and correlates, 1990-1994', Journal of Management, Vol. 24, No. 1, pp.97-117.

Snell, A.S. and Dean, J.W. (1992) 'Integrated manufacturing and human resource management: a human capital perspective', The Academy of Management Journal, Vol. 35, No. 3, pp.467-504.

Wagar, H.T. (1998) 'Determinants of human resource management in small firms: some evidence from Atlantic Canada', Journal of Small Business Management, Vol. 36, pp.13-23.

Wagar, H.T. and Langrock, L. (2004) 'Performance appraisal and compensation in small firms', Canadian HR Reporter, Vol. 12, No. 13, p.10.

Wilkinson, A. (1999) 'Employment relations in SMEs', Employee Relations, Vol. 12, No. 3, pp.206-217.

Wong, C., Marshall, J.N., Aldermart, N. and Thwaites, A. (1997) 'Management training in small and medium-sized enterprises: methodological and conceptual issues', The International Journal of Human Resource Management, Vol. 8, No. 1, pp.44-65. 